\title{
Possible Adverse Effects of Soy Isoflavone Mixture on Pregnant and Lactating Rats and their Suckling Pups
}

\author{
Sachie Ikegami, ${ }^{*, a}$ Yuko Tousen, ${ }^{b}$ Yoshiko Ishimi, ${ }^{c}$ Keizo Umegaki, ${ }^{c}$ and Yoko Nakashima ${ }^{b}$ \\ ${ }^{a}$ Department of Home Economics, Otsuma Women's University, 12 Sanbancho, Chiyoda-ku, Tokyo 102-8357, Japan, ${ }^{b}$ Department of \\ Human Life and Culture, Seitoku University, 550 Iwase, Mastudo, Chiba 271-8555, Japan, and 'Division of Applied Food Science, \\ National Institute of Health and Nutrition, 1-23-1 Toyama, Shinjuku-ku, Tokyo 162-8636, Japan
}

(Received March 27, 2006; Accepted July 26, 2006)

\begin{abstract}
There is general agreement that soy isoflavones can be beneficial to health in adults. However, isoflavones are well known as endocrine-disrupting chemicals. The possibility that soy foods might adversely affect the reproductive system of mothers and infants should be considered. The aim of this study was to evaluate the adverse effects of a soy isoflavone mixture on rat dams and their offspring. The rat dams were fed diets containing the isoflavone mixture (commercial name: Soyact, aglycone type) at $0,0.25,0.5$ and $1.0 \mathrm{~g} / \mathrm{kg}$ as total isoflavones from pregnancy day 5 to postnatal day 13. We found that the dietary soy isoflavone mixture decreased the dam body weights in a dose-dependent manner and that the number of pups also tended to decrease. Genistein and daidzein were detected in the blood of the dams and the stomach contents of the suckling pups. The concentrations of daidzein were higher than those of genistein. We also found the transfer of isoflavones to the fetus. The reproductive output and fetus numbers were not significantly different in the isoflavone groups compared with the control group. The number of absorbed fetuses tended to increase though not significant. Our experiments suggested that soy isoflavones have the possibility of inducing adverse effects on endocrinic functions and others in animal studies at very high doses.
\end{abstract}

Key words — soy isoflavone, genistein, daidzein, pregnant rats, suckling pups

\section{INTRODUCTION}

The possibility that dietary flavonoids may play a role in human health ${ }^{1,2)}$ and the prevention of several diseases, including cancer, ${ }^{3,4)}$ cardiovascular disease $^{5,6)}$ and osteoporosis ${ }^{7)}$ has received considerable attention. Soy isoflavones are of particular interest. The isoflavone components of soy are mainly glycosides of genistein and daidzein. We have published the mechanism of bone formation by genistein in mice. ${ }^{8)}$ We have also reported the adverse effect of genistein at higher levels than those observed the bone formation in ovariectomized mice. ${ }^{9)}$

The structural similarity of soy isoflavones with $17 \beta$-estradiol has prompted many studies on their possible effects on reproductive function and developmental growth. Isoflavones may act like estrogen or antiestrogen, while causing direct and indirect

\footnotetext{
*To whom correspondence should be addressed: Department of Home Economics, Otsuma Women's University, 12 Sanbancho, Chiyoda-ku, Tokyo 102-8357, Japan. Tel. \& Fax: +81-3-52756046; E-mail: sikegami@otsuma.ac.jp
}

toxicological effects on the reproductive organs. Nagata et al. showed that high intake of soy milk may modify circulating estrogens and possibly alter the length of the menstrual cycle. ${ }^{10)}$ Kurzer concluded in a review on the hormonal effects of soy, that soy and isoflavone consumption did not seem to affect the endometrium in premenopausal women, but there may have been weak estrogenic effects. ${ }^{11}$

Some studies have been undertaken to clarify the effects on estrogen-related tissues in rats. In adult rats, Ishimi et al. ${ }^{9}{ }^{9}$ Santell et al. ${ }^{12)}$ Fritz et al ${ }^{13)}$ and Nagao et al ${ }^{14)}$ have observed that dietary genistein increased the uterus weight and affected the prostate. Infant formulas based on soy, breast milk of mothers consuming soy foods and supplements containing isoflavones have been identified in amniotic fluid, meaning placental transfer. Many studies have been performed to clarify the developmental effect of isoflavones on the fetus and offspring. Oral exposure to genistein has been reported to induce a decrease in total body and reproductive organ weights ${ }^{15-17)}$ and cause dysfunction in reproductive behavior ${ }^{17)}$ in the dams and their offspring. Awoniyi 
et al. have indicated that in in utero and lactational exposure, serum levels of estradiol and progesterone of offspring were significantly reduced and the weights of the ovary and uterus decreased. ${ }^{18)}$ Hughes et al. have examined the reproductive outcomes after developmental exposure to isofalvones via a soy milk and genistein in rats. ${ }^{19)}$ Soy milk and genistein exposure induced a significant increase in progesterone receptors in the uterus tissue, while most reproductive endpoints were not significantly modified in pups of either sex. These reports suggest that developmental genistein treatment causes subtle alterations in some kinds of sexually dimorphic behavior. It has also been reported that overall maternal reproductive function, nursing behavior, fetal and infant development were unaffected by oral exposure at low levels. ${ }^{20)}$

It is known that a deficiency of thyroid hormone is produced in infants receiving an exclusively soybased diet. Divi et al. indicated that genistein and daidzein in soy protein inhibited thyroid peroxidase (TPO), an enzyme involved in iodothyronin hormone synthesis. ${ }^{21)}$ It has also been reported that soy isoflavones decreased the serum concentration of thyroid hormones under the deficiency of iodine. ${ }^{22)}$

While some epidemiological data supports the health claims of soy isoflavones, however, the potential to cause adverse effects must be also considered, especially if exposure occurs during the early and critical periods of development and at high concentrations as might be found in some current soy foods and isoflavones products.

In the present study, therefore, we conducted experiments in order to clarify the adverse effects of isoflavones on pregnant and lactating rats.

\section{MATERIALS AND METHODS}

Materials — An isoflavone mixture (commercial name : "Soyact") was kindly given to us by Kikkoman Co. Ltd. (Chiba, Japan). This isoflavone mixture contains daidzein $16.39 \%$, genistein $14.85 \%$ and glycitein $2.03 \%$ as aglycones. The daidzein/ genistein ratio in the mixture was 1.10. Standard genistein and daidzein were purchased from Fujicco Co. Ltd. (Kobe, Japan). Other chemicals were purchased from Wako Pure Chemical (Osaka, Japan) and Sigma-Aldrich Inc. (St. Louis, U.S.A.). Diet components were purchased from Oriental Yeast Co. Ltd. (Tokyo, Japan).

Animals and Diets — Pregnant Sprague-Dawley rats were used in the experiments. Sperm-positive rats (10-w old) were commercially obtained from Japan Crea Co. Ltd. (Tokyo, Japan) on day 5 of pregnancy. They were housed individually in plastic cages in a room kept at a constant temperature (23 \pm $1^{\circ} \mathrm{C}$ ) and illuminated according to a 12-hr light/dark cycles. Rats were fed experimental diets containing Soyact at levels of $0,0.25 .0 .5$ and $1.0 \mathrm{~g} / \mathrm{kg}$ as total isoflavones. These diets were based on the AIN-93G diet $^{23)}$ except for the replacement of soybean oil with corn oil.

The care and use of rats followed the guidelines of Law No. 105 and Notification No. 6 of the Japanese Government. The present study was approved by the Ethical Committee of the National Institute of Health and Nutrition.

\section{Experimental Design}

Experiment 1: Experiment 1 was performed to clarify the effect of the soy isoflavone mixture exposure to dams during pregnancy and lactation and their suckling pups. Pregnant rats were assigned into two groups: the first group was fed the control diet without the isoflavone mixture $(n=4)$. The second group was fed the experimental diets containing the isoflavone mixture at $0.5 \mathrm{~g} / \mathrm{kg}(n=5)$ as total isoflavones. The dams were given free access to the respective diet and water until postnatal day 13 .

Within $24 \mathrm{hr}$ of birth, litters were culled to 10 pups for each dam. Two litters on days 2 and 13 after birth, and dams on day 13 were anesthetized with ether and killed by cardiac puncture. Blood samples were collected and the organs dissected and weighed. These collected samples were frozen immediately and stored at $-20^{\circ} \mathrm{C}$.

Experiment 2: Experiment 2 was performed to clarify the effect of the soy isoflavone mixture exposure on pregnancy, because we observed the tendency of decreased body weights of dams and suckling pups fed the isoflavone mixture in Experiment 1. Eighteen pregnant rats were assigned into three groups of six dams each and fed the control diet and the experimental diets containing the isoflavone mixture at 0.25 and $0.5 \mathrm{~g} / \mathrm{kg}$ as total isoflavones, respectively. The dams were given free access to the respective diet and water during pregnancy. All pregnant dams were killed on the day before parturition. However one rat in the control $(0 \mathrm{~g} / \mathrm{kg})$ group and two rats in $0.5 \mathrm{~g} / \mathrm{kg}$ group were excluded from the experimental data, because of no or a few fetuses.

Experiment 3: In Experiment 2, we had observed the subtle effect of the isoflavone mixture on the pregnancy. Therefore, Experiment 3 was performed 
to clarify and to ascertain the detailed effect of the isoflavone mixture. Twenty pregnant rats were assigned into two groups of ten dams each and pairfed the control diet and the experimental diet containing the isoflavone mixture at $1.0 \mathrm{~g} / \mathrm{kg}$ as total isoflavones.

\section{Analytical Methods}

Isoflavones: Isoflavones in the blood, stomach contents, placenta and fetus were previously treated with $\beta$-glucuronidase (Sigma, Type H-2) to be hydrolyzed according to the method of Gamache and Acworth. ${ }^{24)}$ The total isoflavone contents in the isoflavone mixture, placenta, fetus, blood and stomach contents were determined by high-performance liquid chromotography (HPLC) analytical method reported by Franke et al. ${ }^{25)}$ The analytical results were shown as genistein and daidzein aglycones.

Thyroid Hormones: The measurement of serum thyroid hormones, $\mathrm{T}_{3}$ (triiodothyronine), $\mathrm{T}_{4}$ (thyrotine), and thyroid stimulating hormone (TSH) was performed by a testing center (SRL Co. Ltd., Tokyo).

Statistical Analysis — Data is presented as individual group means \pm S.D. Statistical analysis was conducted by one-way analysis of variance (ANOVA). Differences in mean values between groups were tested by using Duncan's multiple range test in Experiment 2, and Student- $t$ test in Experiment 1 and 3 . The differences were considered significant at $p<0.05$.

\section{RESULTS}

\section{Experiment 1}

The food intakes, body weights and relative organ weights of dams fed the diets containing isoflavone mixture at 0 (control) and $0.5 \mathrm{~g} / \mathrm{kg}$ diet and their suckling pups are shown in Table 1. The numbers of suckling pups born of dams fed the control diet and $0.5 \mathrm{~g} / \mathrm{kg}$ isoflavone mixture diet were $(16,12,15$, and 15$)$ and $(12,15,12,12$, and 9$)$, respectively. Changes in body weights during the periods of pregnancy and nursing are shown in Fig. 1. During both periods, maternal body weight tends to be suppressed by the isoflavone mixture. As shown in Table 1, the food intakes during pregnancy and lactation in the isoflavone group were lower than those in the control group. The liver weight of dams in isoflavone group was higher than the control group.

The body weights of suckling pups on the days
2 and 13 after birth in isoflavone group were lower than in the control group, but not significantly so. The changes in the body weights of pups are shown in Fig. 2. The growth curve of suckling pups was suppressed by feeding the isoflavone mixture to the dams. The concentrations of isoflavones in the blood of dams and in the pup stomach contents and in the blood of suckling pups are shown in Fig. 3. The concentrations of daidzein in the samples were higher than those of genistein. The concentrations of diaidzein and genistein in the blood of suckling pups were lower than those of the dams. Isoflavone concentrations in the stomach contents of suckling pups at day 2 were very lower than those at day 13 .

Table 2 shows the concentrations of thyroid hormones in the dams fed the isoflavone diets and their pups. The concentrations of $\mathrm{T}_{3}$ and $\mathrm{T}_{4}$ in dams fed isoflavone diet were not significantly different to those on the control diet. No significant difference was shown in the concentrations of thyroid hormones in the suckling pups among the groups, but the concentration of TSH in the isoflavone diet groups tended to be higher.

\section{Experiment 2}

Experiment 2 was performed to ascertain the effect of the isoflavone mixture on the reproductive function. In this experiment, lower levels of isoflavones and a larger number of dams were selected based on the results in Experiment 1. Table 3 shows the food intake and the body weight of dams, and weight and height of their fetuses. The effect on the reproductive output in this experiment could not be ascertained. The fetus numbers were not significantly different among the three groups.

Body weights of dams fed the isoflavone diets were lower at $0.5 \mathrm{~g} / \mathrm{kg}$ level than at 0 and $0.25 \mathrm{~g} / \mathrm{kg}$ and also the food intake in $0.5 \mathrm{~g} / \mathrm{kg}$ isoflavone diet group was lower than those of other groups. The fetal weights, heights and anogenital distances were not significantly different among the three groups.

The concentrations of thyroid hormones in this experiment are shown in Table 4. No significant effect on thyroid hormones was indicated in this experiment. The concentrations of isoflavones in the blood, placenta and fetus of dams fed the isoflavone mixture diets are shown in Fig. 4. The concentrations of daidzein and genistein in the blood were similar to the results found in Experiment 1. The concentrations in the placenta and fetus were much lower than those in the blood. Concentrations of isoflavones in the blood, placenta and fetus were 
Table 1. Body and Organ Weights of Dams Fed the Diets Containing Isoflavones at 0 and $0.5 \mathrm{~g} / \mathrm{kg}$ Diet and those of their Suckling Pups in Experiment $\left.1^{a}\right)$

\begin{tabular}{|c|c|c|c|c|c|}
\hline & \multicolumn{5}{|c|}{ Isoflavones treatment $(\mathrm{g} / \mathrm{kg})$} \\
\hline & \multicolumn{2}{|r|}{0} & \multicolumn{3}{|c|}{0.5} \\
\hline Dams $\left.(\mathrm{n})^{b}\right)$ & \multicolumn{2}{|r|}{4} & \multicolumn{3}{|c|}{5} \\
\hline Food intake for pregnancy $(\mathrm{g})$ & 321 & \pm 32 & 277 & \pm & $50^{*}$ \\
\hline Food intake for lactation $(\mathrm{g})$ & 381 & \pm 46 & 332 & \pm & $46^{*}$ \\
\hline Body weight (g) & 302 & \pm 14 & 271 & \pm & 29 \\
\hline Liver weight $\left.(\mathrm{g} / 100 \mathrm{~g})^{c}\right)$ & 4.42 & \pm 0.26 & 5.20 & \pm & $0.48 *$ \\
\hline Kidney weight (g/100g) & 0.66 & \pm 0.05 & 0.62 & \pm & 0.03 \\
\hline Brain weight $(\mathrm{g} / 100 \mathrm{~g})$ & 0.61 & \pm 0.05 & 0.69 & \pm & 0.06 \\
\hline Spleen weight (g/100g) & 0.21 & \pm 0.02 & 0.23 & \pm & 0.03 \\
\hline Thymus weight (g/100g) & 0.06 & $\pm \quad 0.02$ & 0.05 & \pm & 0.02 \\
\hline \multicolumn{6}{|l|}{ Suckling pups ${ }^{d)}$} \\
\hline On day 2 after birth (n) & \multicolumn{2}{|r|}{6} & \multicolumn{3}{|c|}{8} \\
\hline Body weight (g) & 7.12 & \pm 0.76 & 7.13 & \pm & 1.27 \\
\hline Liver weight $(\mathrm{g} / 100 \mathrm{~g})$ & 4.20 & \pm 0.52 & 4.48 & \pm & 0.22 \\
\hline Kidney weight $(\mathrm{g} / 100 \mathrm{~g})$ & 1.05 & \pm 0.09 & 1.03 & \pm & 0.13 \\
\hline Brain weight $(\mathrm{g} / 100 \mathrm{~g})$ & 3.68 & \pm 0.30 & 3.90 & \pm & 0.48 \\
\hline Spleen weight $(\mathrm{g} / 100 \mathrm{~g})$ & 0.16 & \pm 0.03 & 0.19 & \pm & 0.04 \\
\hline Thymus weight $(\mathrm{g} / 100 \mathrm{~g})$ & 0.18 & $\pm \quad 0.05$ & 0.15 & \pm & 0.04 \\
\hline On day 13 after birth (n) & \multicolumn{2}{|r|}{16} & \multicolumn{3}{|c|}{20} \\
\hline Body weight (g) & 35.1 & \pm 2.0 & 30.5 & \pm & 2.4 \\
\hline Liver weight $(\mathrm{g} / 100 \mathrm{~g})$ & 2.95 & \pm 0.16 & 2.84 & \pm & 0.16 \\
\hline Kidney weight (g/100g) & 1.10 & \pm 0.07 & 1.04 & \pm & 0.08 \\
\hline Brain weight $(\mathrm{g} / 100 \mathrm{~g})$ & 3.20 & \pm 0.19 & 3.73 & \pm & $0.20 *$ \\
\hline Spleen weight $(\mathrm{g} / 100 \mathrm{~g})$ & 0.46 & \pm 0.07 & 0.35 & \pm & $0.03 *$ \\
\hline Thymus weight $(\mathrm{g} / 100 \mathrm{~g})$ & 0.30 & \pm 0.03 & 0.31 & \pm & 0.05 \\
\hline
\end{tabular}

a) All values represent means \pm S.D. Within a row, values with asterisk are significantly different from the control group at $p<0.05 . b$ ) The dams were killed by cardiac puncture on postnatal day 13 . c) $\mathrm{g} / 100 \mathrm{~g}$ body weight. $d$ ) Numbers of pups born of dams fed the diets containing isoflavones $0 \mathrm{~g}$ group (4 dams) and $0.5 \mathrm{~g}(5 \mathrm{dams})$ group were $(16,12,15,15)$ and $(12,15,12,12,9)$, respectively.

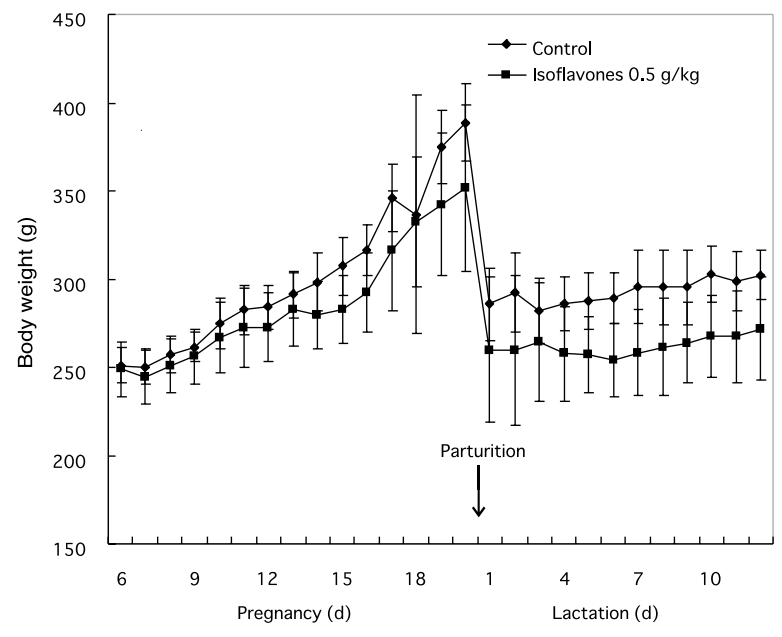

Fig. 1. Changes in the Body Weights of Dams fed the Diets Containing Total Isoflavones at 0 , and $0.5 \mathrm{~g} / \mathrm{kg}$ Diet in Experiment 1

The pregnancy period was from pregnancy day 6 to pregnancy day 21 . The lactation period was from lactation day 1 to lactation day 13 after parturition.

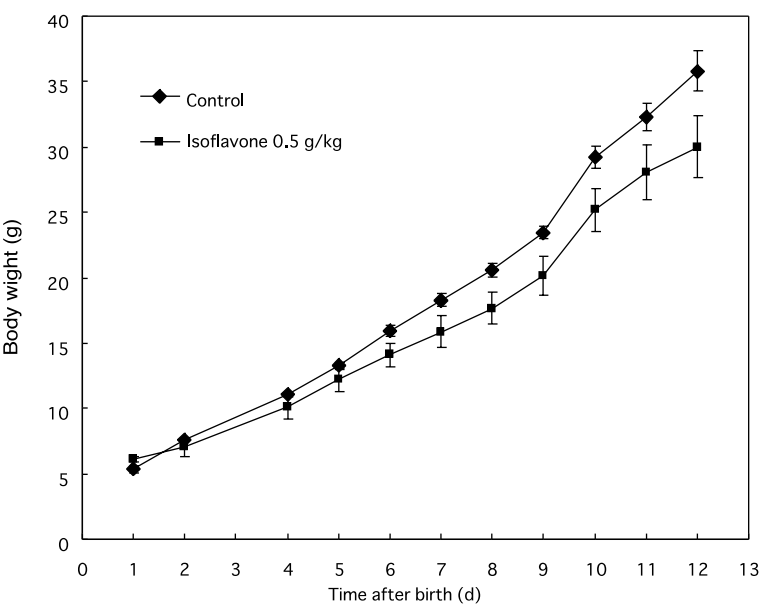

Fig. 2. Changes in the Body Weights of Suckling Pups of Dams Fed the Diets Containing Total Isoflavones at 0 , and $0.5 \mathrm{~g} / \mathrm{kg}$ Diet in Experiment 1

Within $24 \mathrm{hr}$ of birth, litters were culled 10 pups for each dam. As two litters on $\mathrm{d} 2,7$ and 13 after birth, the body weights were calculated from live pups in each day. 


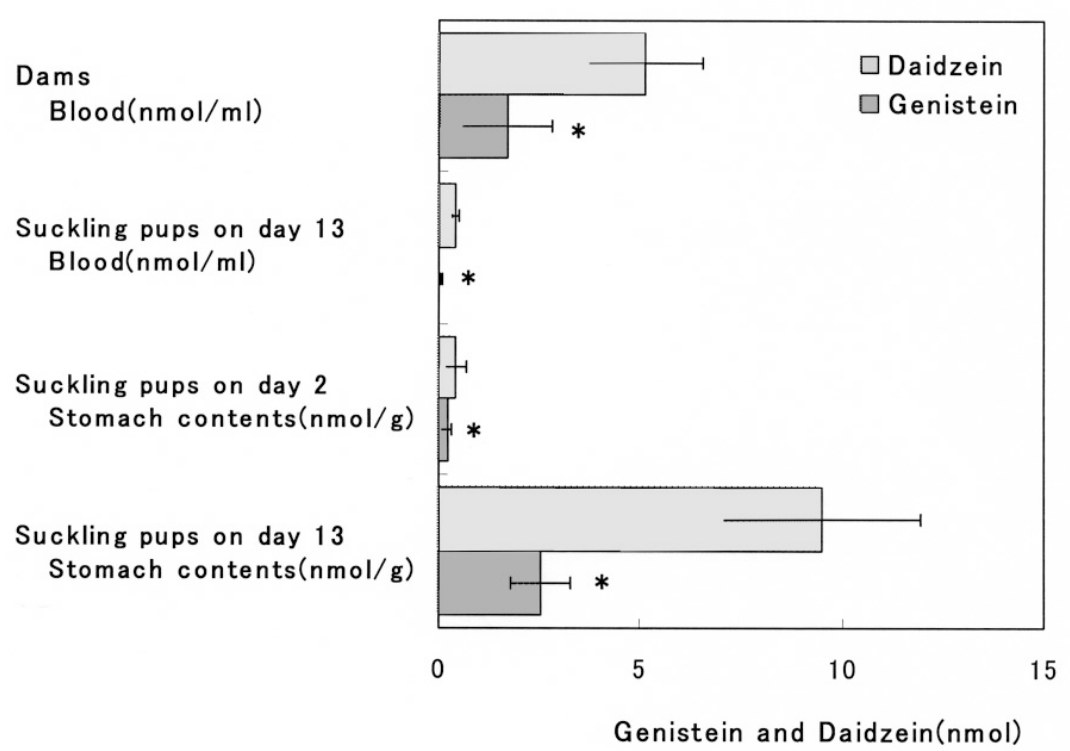

Fig. 3. Concentrations of Isoflavones in Blood of Dams Fed the Diets Containing Isoflavones at 0 , and $0.5 \mathrm{~g} / \mathrm{kg}$ Diet and those in Stomach Contents and Blood of their Suckling Pups in Experiment 1

Within $24 \mathrm{hr}$ of birth, litters were culled 10 pups for each dam. Two litters from each dam on d 2 and 13 after birth and dams on postnatal 13 were killed by cardiac puncture. ${ }^{*}$ : significantly different $(p<0.05)$.

Table 2. Concentrations of $\mathrm{T}_{3}, \mathrm{~T}_{4}$, TSH and Luteinizing Hormone (LH) in Blood of Dams Fed the Diets Containing Isoflavones at 0 and $0.5 \mathrm{~g} / \mathrm{kg}$ Diet and those of their Suckling pup in Experiment $1^{a}$ )

\begin{tabular}{|c|c|c|}
\hline & \multicolumn{2}{|c|}{ Isoflavone treatment $(\mathrm{g} / \mathrm{kg})$} \\
\hline & 0 & 0.5 \\
\hline Dams (n)2 & 4 & 4 \\
\hline $\mathrm{T}_{3}(\mathrm{ng} / \mathrm{ml})$ & $0.80 \pm 0.08$ & $0.80 \pm 0.08$ \\
\hline $\mathrm{T}_{4}(\mathrm{pg} / \mathrm{ml})$ & $39.3 \pm 1.09$ & $40.5 \pm 0.61$ \\
\hline TSH (ng/ml) & $6.80 \pm 0.82$ & $7.30 \pm 1.30$ \\
\hline LH (ng/ml) & $2.30 \pm 0.18$ & $2.28 \pm 0.05$ \\
\hline \multicolumn{3}{|l|}{ Suckling pups } \\
\hline On day 13 after birth (n) & 8 & 8 \\
\hline $\mathrm{T}_{3}(\mathrm{ng} / \mathrm{ml})$ & $0.90 \pm 0.08$ & $0.85 \pm 0.09$ \\
\hline $\mathrm{T}_{4}(\mathrm{pg} / \mathrm{ml})$ & $54.4 \pm 0.57$ & $53.1 \pm 0.50$ \\
\hline TSH (ng/ml) & $6.90 \pm 0.88$ & $8.13 \pm 1.96$ \\
\hline $\mathrm{LH}(\mathrm{ng} / \mathrm{ml})$ & $2.09 \pm 0.68$ & $2.21 \pm 0.55$ \\
\hline
\end{tabular}

a) All values are means \pm S.D. $b$ ) The dams were killed by cardiac puncture on postnatal day 13 .

proportional to their dose levels.

\section{Experiment 3}

The results obtained from Experiment 1 showed the possible adverse effect of isoflavone mixture on the reproductive function. The adverse effect could not be ascertained in Experiment 2. Therefore, Experiment 3 was performed to try to ascertain the ef- fect by increasing the number of dams and isoflavone contents in the diet, and by pair-feeding.

The body, placenta and fetus weights in Experiment 3 are shown in Table 5. In Experiment 3, a decrease in the body weight of dams in the isoflavone group was observed in spite of the same food intakes in the control and isoflavone groups because of pair-feeding. This result shows that isoflavone mixture suppresses the body weight gain of dams. However the weights of the placenta and fetus were not significantly different between the control and isoflavone groups. In this experiment, the number of absorbed fetus tended to increase although not significantly.

\section{DISCUSSION}

There is general agreement that soy-rich diets can be beneficial to adults, but the benefits of feeding infants soy-based formulas have been debated. The basis of this controversy is that soy products generally contain isoflavones, which can affect the development of the reproductive system.

In Experiment 1, we found isoflavones in the serum and stomach contents of the suckling pups and in Experiment 2 and 3, we observed the transfer of isoflavones to the fetus. Ratio of daidzein/ genistein in the isoflavone mixture used in this study 
Table 3. Body and Placenta Weights of Dams Fed the Diets Containing Isoflavones at $0,0.25$ and $0.5 \mathrm{~g} / \mathrm{kg}$ Diet and Body Weight, Heights and Anogenical Distance of their Fetus on Pregnant day 20 in Experiment $2^{a}$ )

\begin{tabular}{|c|c|c|c|c|c|c|c|c|c|}
\hline \multirow{3}{*}{ Dams (n) $)^{b)}$} & \multicolumn{9}{|c|}{ Isoflavone treatment $(\mathrm{g} / \mathrm{kg})$} \\
\hline & \multicolumn{3}{|c|}{0} & \multicolumn{3}{|c|}{0.25} & \multicolumn{3}{|c|}{0.5} \\
\hline & \multicolumn{3}{|c|}{5} & \multicolumn{3}{|c|}{6} & \multicolumn{3}{|c|}{4} \\
\hline Food intake $(\mathrm{g})$ & 380 & & 39 & 375 & \pm & 15 & 309 & & $32 *, * *$ \\
\hline Body weight (g) & 423 & & 28 & 419 & \pm & 21 & 371 & \pm & $47 *, * *$ \\
\hline Placenta weight (g) & 0.506 & \pm & 0.060 & 0.542 & \pm & 0.168 & 0.568 & \pm & 0.270 \\
\hline \multicolumn{10}{|l|}{ Fetus $^{b)}$} \\
\hline Number/dam ${ }^{c)}$ & 14.2 & \pm & 6.3 & 15.7 & \pm & 2.9 & 11.3 & \pm & 7.8 \\
\hline Body weight (g) & 3.92 & & 0.65 & 3.81 & \pm & 0.29 & 4.00 & \pm & 0.35 \\
\hline Height $(\mathrm{cm})$ & 4.40 & & 0.26 & 4.37 & \pm & 0.15 & 4.42 & \pm & 0.39 \\
\hline \multicolumn{10}{|l|}{ Anogenital distance } \\
\hline Male (mm) & 4.36 & & 0.31 & 4.24 & \pm & 0.33 & 4.31 & \pm & 0.24 \\
\hline Female $(\mathrm{mm})$ & 2.46 & \pm & 0.21 & 2.47 & \pm & 0.21 & 2.51 & \pm & 0.17 \\
\hline \multicolumn{10}{|c|}{ Anogenital distance/height } \\
\hline Male & 0.098 & & 0.007 & 0.096 & \pm & 0.007 & 0.097 & \pm & 0.006 \\
\hline Female & 0.058 & & 0.006 & 0.058 & \pm & 0.005 & 0.058 & \pm & 0.004 \\
\hline
\end{tabular}

a) All values represent means \pm S.D. $b$ ) Dams having fetus less than 3 were excluded from the data. $c$ ) Number of fetuses contains those less than $3 .{ }^{*} p<0.05$ compared with $0 \mathrm{~g} / \mathrm{kg}$ diet. ${ }^{*} p<<0.05$ compared with $0.25 \mathrm{~g} / \mathrm{kg}$ diet.

Table 4. Concentrations of $\mathrm{T}_{3}, \mathrm{~T}_{4}$ and TSH and $\mathrm{LH}$ in Blood of Dams Fed the Diet Containing Isoflavones at $0,0.25$ and $0.5 \mathrm{~g} / \mathrm{kg}$ Diet on Pregnant day 20 in Experiment $2^{a)}$

\begin{tabular}{lrrr}
\hline \hline & \multicolumn{3}{c}{ Isoflavones treatment $(\mathrm{g} / \mathrm{kg})$} \\
\cline { 2 - 4 } & \multicolumn{1}{c}{0} & \multicolumn{1}{c}{0.25} & 0.5 \\
\hline $\mathrm{T}_{3}(\mathrm{ng} / \mathrm{ml})$ & $0.98 \pm 0.08$ & $1.07 \pm 0.20$ & $1.07 \pm 0.12$ \\
$\mathrm{~T}_{4}(\mathrm{pg} / \mathrm{ml})$ & $25.0 \pm 0.28$ & $23.8 \pm 0.83$ & $28.0 \pm 0.89$ \\
$\mathrm{TSH}(\mathrm{ng} / \mathrm{ml})$ & $5.67 \pm 0.98$ & $6.27 \pm 0.71$ & $6.62 \pm 1.32$ \\
$\mathrm{LH}(\mathrm{ng} / \mathrm{ml})$ & $1.35 \pm 0.36$ & $1.49 \pm 0.35$ & $1.53 \pm 0.52$ \\
\hline
\end{tabular}

a) All values are means \pm S.D.

was 1.10. However, the ratios in all biological samples were higher compared with the mixture. In the Experiment 1, for example, the ratio in dam serum was 3.00, while those in the stomach contents and the serum of 13 days-old pup were 3.77 and 5.75, respectively. On the other hand, in Experiment 2, the ratios of the fetuses in $0.25 \mathrm{~g} / \mathrm{kg}$ and $0.5 \mathrm{~g} / \mathrm{kg}$ groups were 4.47 and 3.77. The results showed that genistein was rapidly metabolized and excreted compared with daidzein, and therefore genistein contents were getting to be low in order of dam serum, pup stomach contents and the fetus or pup serum.

In the present study, we observed no obvious parturition outcome in the dams fed the diet containing the isoflavone mixture. Onozawa et al. ${ }^{26)}$ administered an isoflavone mixture at $500 \mu \mathrm{g} / \mathrm{g}$ body weight, but they did not observe the effect on reproductive function. We gave the diets containing isoflavone mixture at $0.25,0.5$, and $1.0 \mathrm{~g} / \mathrm{kg}$ to the pregnant and lactating dams. The dose level in Onozawa et al. study ${ }^{26)}$ was higher compared to those in our study. Other studies also showed insignificant effects of isoflavones on the reproductive function. Winsniewski et al. ${ }^{27)}$ and Lamartiniere et al., ${ }^{28)}$ however, have reported that genistein and daidzein did have some effect on the reproductive organs and productive capacity. Further studies may well be needed to clarify this issue.

Our study showed suppressed body weights and food intakes of dams and suckling pups in the isoflavone group. However, Experiment 3 revealed that isoflavone mixture suppressed the body weight 


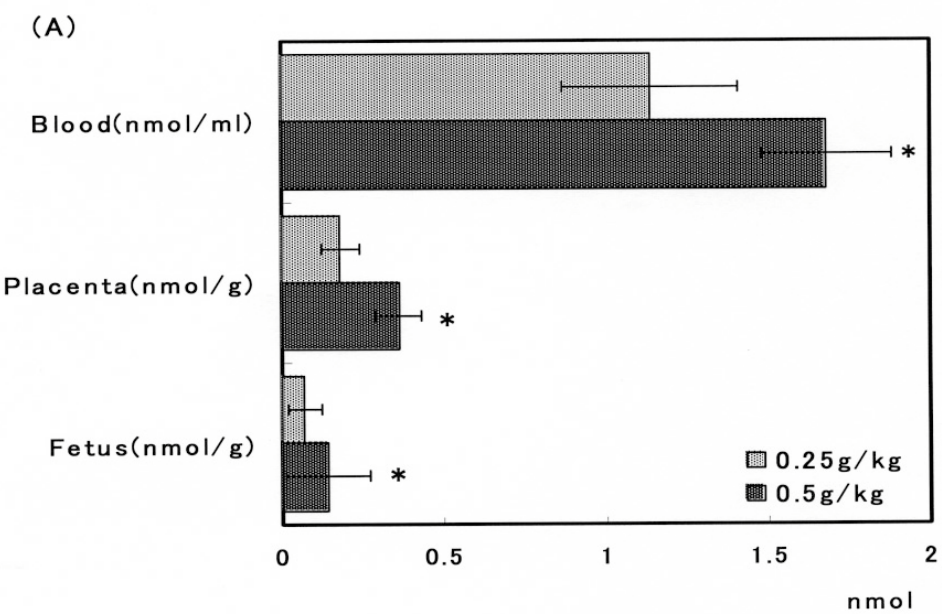

(B)

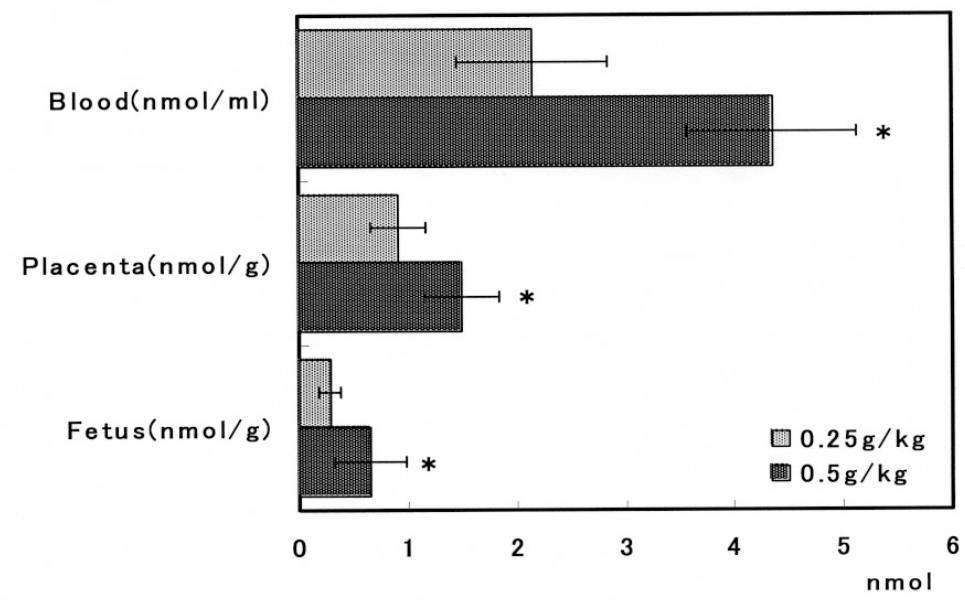

Fig. 4. Concentrations of Isoflavones in Blood and Placenta of Pregnant Rats Fed the Diet containing Isoflavones at $0,0.25 \mathrm{and} 0.5 \mathrm{~g} / \mathrm{kg}$ Diet and that in their Fetuses on Pregnant day 20 in Experiment 2

(A): Genistein, (B): Daidzein. *: significantly different $(p<0.05)$

Table 5. Body and Placenta Weights of Dams Fed the Diet Containing Isoflavones at 0 and $1.0 \mathrm{~g} / \mathrm{kg}$ Diet and Fetus Weight, Number of Absorption on Pregnant day 20 in Experiment $3^{a}$ )

\begin{tabular}{|c|c|c|c|c|}
\hline & \multicolumn{4}{|c|}{ Isoflavones treatment $(\mathrm{g} / \mathrm{kg})$} \\
\hline & & 0 & & 1.0 \\
\hline \multicolumn{5}{|l|}{ Dams } \\
\hline $\mathrm{N}$ & \multicolumn{2}{|r|}{10} & \multicolumn{2}{|r|}{10} \\
\hline Food intake (g) & 199 & \pm 5 & 200 & \pm 5 \\
\hline Body weight (g) & 340 & \pm 15 & 315 & $\pm 31^{*}$ \\
\hline Placenta (g) & \multicolumn{2}{|c|}{$0.453 \pm 0.051$} & \multicolumn{2}{|c|}{$0.470 \pm 0.032$} \\
\hline \multicolumn{5}{|l|}{ Fetus } \\
\hline Numbers/dam & 16.2 & \pm 2.0 & 14.6 & \pm 4.2 \\
\hline Weight (g) & 3.39 & \pm 0.25 & 3.4 & \pm 0.48 \\
\hline Number of absorption & 0.9 & \pm 1.3 & 2.1 & \pm 2.3 \\
\hline
\end{tabular}

a) All values represent means \pm S.D. Within a row, values with asterisk are significantly different from the control group at $p<0.05$. 
gain even at the same food intake under pair-feeding condition. Some reports have shown that isoflavones and genistein reduced the food intake in rats and mice. ${ }^{15,29)}$ Our result also revealed an effect of isoflavones on body weight gain induced partially by reduced food intake and partially by other mechanisms. Nogowski et al..$^{30)}$ demonstrated that dietary genistein had a direct effect on lipid metabolism in liver and adipose tissues in decreasing triglycerides. It was shown that genistein induced lypolysis and inhibited de novo lipid synthesis in 3T3-L1 adipocytes. ${ }^{30)}$

Our study showed no effect of the isoflavone mixture on the serum thyroid hormone. Deficiency of the thyroid hormone is known to produce goiter in humans and has been reported in infants receiving an exclusively soy-based diet. ${ }^{31)}$ Results of a biochemical study by Divi et al. ${ }^{21)}$ indicated that genistein and daidzein in soy protein inhibited TPO, an enzyme involved in iodothyronine hormone synthesis. Chang and Doerge ${ }^{32)}$ performed a study in which male and female rats were fed the soy present NIH 31 feed which contains approximately $30 \mathrm{ppm}$ each of genistein and daidzein. Their study showed the loss of more than $50 \%$ of TPO activity. The inhibition was abolished in the presence of iodide ions. ${ }^{22)}$

Chang and Doerge also reported that in rats exposed to genistein in the diet for 20 weeks, the activities of TPO in male and females were reduced, but there were no differences in thyroid hormone levels in serum, thyroid weights, and histopathology between the genistein-treated and untreated groups. ${ }^{32)}$ These results suggested that even though substantial TPO activity was sufficient to maintain thyroid hormone homestasis.

In this study, we did not determine the difference in the effect between male and female pups. Previous reports have suggested that soy isoflavones might have some adverse effects mainly on the pregnant animals and their suckling pups (both male and female). ${ }^{20)}$ Faqi et al. ${ }^{33)}$ however, observed that a soy isoflavones mixture had no effect on body weight and reproductive parameter of adult rats even at high level $(2000 \mathrm{mg} / \mathrm{kg}$ diet $)$. It is likely therefore that dietary isoflavones might mainly influence the dams and their pups.

Our results showed the possibility of adverse effects on endocrine functions and /or others in an animal study at doses well in excess of levels normally associated with human dietary intake. Japanese mean intake of soy isoflavones was reported to be $30 \mathrm{mg} / \mathrm{day}(0.5 \mathrm{mg} / \mathrm{kg}$ body weight $){ }^{34)}$ In this study, dams have ingested approximately $100 \mathrm{mg} /$ $\mathrm{kg}$ body weight, two hundred fold increase in the mean Japanese intake ratio. Therefore the results of this study can not be directly extrapolated or applied to an effect on the human body.

As Soyact used in this study is utilized for healthy foods, it is important to ascertain its safety. There is a large variability of isoflavone composition among soybeans, soy-based food products and healthy foods, and most dietary sources contain a mixture of pre-dominantly glucosides of genistein and daidzein. There is a well-known difference between the two isoflavones in terms of their metabolism and affinity to estrogen receptors. Further studies are therefore needed to clarify the difference in the biological effects of these two isoflavones.

Acknowledgements This study was supported by Health Science Research grants from the Ministry of Health and Welfare, Japan.

\section{REFERENCES}

1) Setchell, K. D. R. and Cassidy, A. (1999) Dietary isoflavones: Biological effects and relevance to human health. J. Nutr., 129, 758S-767S.

2) Setchell, K. D. R. (1998) Phytoestrogens: the biochemistry, physiology, and implications for human health of soy isoflavones. Am. J. Clin. Nutr., 68 (suppl), 1333S-1346S.

3) Yamamoto, S., Sobue, T., Kobayashi, M., Sasaki, S. and Tsugane, S. (2003) Soy, isoflavones, and breast cancer risk in Japan. J. Natl. Cancer Inst., 95, 906-913.

4) Magee, P. J. and Rowland, I. R. (2004) Phytooestrogens, their mechanism of action: current evidence for a role in breast and prostate cancer. $B r . J$. Nutr., 91, 513-531.

5) Merz-Demlow, B. E., Duncan, A. M., Wangen, K. E., Xu X., Carr, T. P., Phipps, W. R. and Kurzer, M. S. (2000) Soy isoflavones improve plasma lipids in normocholestrolemic, premenopausal women. Am. J. Clin. Nutr., 71, 1462-1469.

6) Lichtenstein, A. H. (1998) Soy protein, isoflavones and cardiovascular disease risk. J. Nutr., 128, 15891592.

7) Greendale, G. A., FitzGerald, G., Huang, M-H., Sternfeld, B., Gold, E., Seeman, T., Sherman, S. and Sowers, M. F. (2002) Dietary soy isoflavones and bone mineral density: Results from the study of Women's Health Across the Nation. Am. J. Epidmiol., 155, 746-754. 
8) Ishimi, Y., Miyaura. C., Ohmura, M., Onoe, Y., Sato, T., Uchiyama, Y., Ito, M., Wang, X., Suda, T. and Ikegami, S. (1999) Selective effects of genistein, a soybean isoflavone, on B-lymphopoiesis and bone loss caused by estrogen deficiency. Endocrinology, 140, 1893-1900.

9) Ishimi, Y., Arai, N., Wang, X., Wu, J., Umegaki, K., Miyaura, C., Takeda, A. and Ikegami, S. (2000) Difference in effective dosage of genistein on bone and uterus in ovariectomized mice. Biochem. Biophys. Res.Commun., 274, 697-701.

10) Nagata, C., Takatsuka, N., Inaba, S., Kawakami, N. and Shimizu, H. (1998) Effect of soymilk consumption on serum estrogen concentrations in premenopausal Japanese women. J. Natl. Cancer Inst., 90, 1830-1835.

11) Kurzer, M. S. (2002) Hormonal effects of soy in premenopausal women and men. J. Nutr., 132, 570S573S.

12) Santell, R. C., Chang, Y. C., Nair, M. G. and Helferich, W. G. (1997) Dietary genistein exerts estrogenic effects upon the uterus, mammary gland and the hypothalamic/pituitary axis in rats. J. Nutr., 127, 263-269.

13) Fritz, W. A., Eltoum. I-E., Cotroneo, M. S. and Lamartiniere, C. A. (2002) Genistein alters growth but is not toxic to the rat prostate. J. Nutr., 132, 30073011.

14) Nagao, T., Yoshimura, S., Saito, Y., Nakagomi, M., Usumi, K. and Ono, H. (2001) Reproductive effects in male and female rats of neonatal exposure to genistein. Reprod. Toxicol., 15, 399-411.

15) Delclos, K. B., Bucci, T. J., Lomax, L. G., Latendresse, J. R., Warbritton, A., Weis, C. C. and Newbold, R. R. (2001) Effects of dietary genistein exposure during development on male and female CD (Sprague-Dawley) rats. Reprod. Toxicol., 15, 647-663.

16) Flynn, K. M., Ferguson, S. A., Delclos, K. B. and Newbold, R. R. (2000) Effects of genistein exposure on sexually dimorphic behaviors in rats. Toxicol. Sci., 55, 311-319.

17) Wisniewski, A. B., Klein, S. L., Lakshmanan, Y. and Gearhart, J. P. (2003) Exposure to genistein during gestation and lactation demasculinizes the reproductive system in rats. J. Urol., 169, 1582-1586.

18) Awoniyi, C. A., Roberts, D., Veeramachaneni, D. N., Hurst, B. S., Tucker, K. E. and Schlaff, W. D. (1998) Reproductive sequelae in female rats after in utero and neonatal exposure to the phytoestrogen genistein. Fertil. Steril., 70, 440-447.

19) Hughes, C. L., Liu, G., Beall, S., Foster, W. G. and Davis, V. (2004) Effects of genistein or soy milk during late gestation and lactation on adult uterine organization in the rat. Exp. Biol. Med. (Maywood,
MJ, U. S.), 229, 108-117.

20) Kang, K. S., Che, J. H. and Lee, Y. S. (2002) Lack of adverse effects in the F1 offspring maternally exposed to genistein at human intake dose level. Food Chem. Toxicol., 40, 43-51

21) Divi, R. L., Chang, H. C. and Doerge, D. R. (1997) Anti-thyroid isoflavones from soybean: isolation, characterization, and mechanisms of action. Biochem. Pharmacol., 15, 1087-1096.

22) Kimura, S., Suwa, J., Ito, M. and Sato, H. (1976) Development of malignmant goiter by defatted soybean with iodine free diet in rats. Gann, 67, 763765.

23) Reeves, P. G., Nielsen, F. H. and Fahey, G. C, (1993) AIN-93G purified diets for laboratory rodents: final report of the American Institute of Nutrition ad hoc writing committee on the reformulation of the AIN-76A rodent diet. J. Nutr., 123, 1939-1951.

24) Gamache, P. H. and Acworth, L. N. (1998) Analysis of phytoestrogens and polyphenols in plasma, tissue, and urine using HPLC with coulometric array detection. Proc. Soc. Exp. Biol. Med., 217, 274-280.

25) Franke, A. A., Custer, L. J. and Tanaka Y. (1998) Isoflavones in human breast milk and other biological fluids. Am. J. Clin. Nutr., 68 (supp), 1466S$1473 \mathrm{~S}$.

26) Onozawa, M., Kawamori, T., Baba, M., Fukuda, K., Toda, T., Sato, H., Ohtani, M., Akazawa, H., Sugimura, T. and Wakabayashi, K. (1999) Effects of a soybean isoflavone mixture on carcinogenesis in prostate and seminal vesicules of F334 rats. Jpn. J. Cancer Res., 90, 393-398.

27) Wisniewski, A. B., Cernetich, A., Gearhart, J. P. and Klein, S. L. (2005) Perinetal exposure to genistein alters reproductive development and aggressive in male mice. Physiol. Bihav., 84, 327-334.

28) Lamartiniere, C. A., Wang, J., Smith-Johnson, M. and Eltoum, I. E.(2002) Daidzein: bioavailability, potential for reproductive toxicity, and breast cancer chemoprevention in female rats. Toxicol. Sci., 65, 228-238.

29) Kim, H.-K., Nelson-Dooley, C., Della-Fera, M. A., Yang, J.-Y., Zhang, W., Duan, J., Hartzell, D., L., Hamrick, M. W. and Baile, C. A. (2006) Genistein decreases food intake, body weight, and fat pad weight and causes adipose tissue apoptosis in ovariectomized female mice. J. Nutr., 136, 409-414.

30) Nogowski, L., Mackowisk, P., Kandulska, K., Szkudelski, T. and Nowak, K. W. (1996) Genisteininduced changes in lipid metabolism of ovariectomized rats. Ann. Nutr. Metab., 42, 360-366.

31) Fort, P., Moses, N., Fasano, M., Goldberg, T. and Lifshitz, F. (1990) Breast and soy-formula feeding in early infancy and the prevalence of autoimmune thyroid disease in children. J.Am. Coll.Nutr., 9, 164- 
167.

32) Chang, H. C. and Doerge, D. R. (2000) Dietary genistein inactivates rat thyroid peroxidase in vivo without hypothyroid effect. Toxicol. Appl. Pharmacol., 168, 244-252.

33) Faqi, A. S., Johnson, W. D., Morrissey, R. and McCormick, D. L. (2004) Reproductive toxicity as- sessment of chronic dietary exposure to soy isoflavones in male rats. Reprod. Toxicol., 18, 605611.

34) Novel Foods Expert Committee, The Food Safety Commission (2006) Basic Aspects for Safety Assessment of "Foods for Specified Health Use" Containing Soy Isoflavones, pp.16-17. 